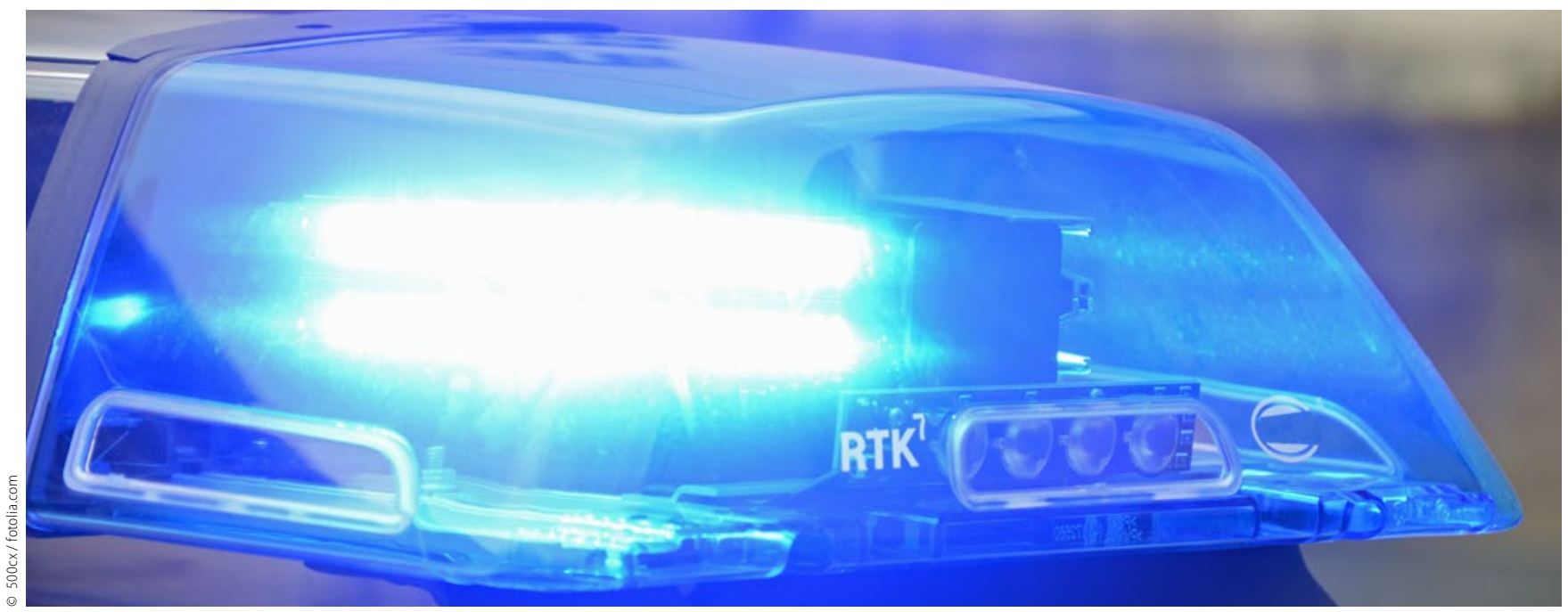

\title{
Zweite Praxis verdoppelt die Notdienstpflichten nicht
}

\begin{abstract}
Die Heranziehung von Vertragszahnärzten zum zahnärztlichen Notdienst bedeutet einen nicht unerheblichen Eingriff in die Berufsfreiheit des betroffenen Zahnarztes. Dies zeigt ein Urteil des Landessozialgerichtes (LSG) Baden-Württemberg (Az. L 5 KA 3306/12).
\end{abstract}

Die beiden Kläger, die gemeinsam mit einem dritten Partner eine zahnärztliche Gemeinschaftspraxis führen, wehrten sich gegen den Umfang, mit dem sie zum zahnärztlichen Notdienst herangezogen wurden. Die Gemeinschaftspraxis hatte wenige Jahre vor Erhebung der Klage eine im selben Notfalldienstbereich rund 16 Kilometer entfernt liegende Zweigpraxis eröffnet. Die Kassenzahnärztliche Vereinigung (KZV) hatte diese unter der Bedingung genehmigt, dass jeder der beteiligten Zahnärzte jeweils zwei Drittel seiner Sprechstundentätigkeit am „Stammsitz" auszuüben habe, um dort die vertragszahnärztliche Versorgung nicht zu gefährden.

Bei der Einteilung zum Notfalldienst wurden die Kläger sowohl mit ihrem eigentlichen Vertragszahnarztsitz als auch mit der Zweigpraxis in vollem Umfang berücksichtigt. Im Ergebnis wurden die drei Zahnärzte also wie sechs Zahnärzte im Turnus der Einteilung herangezogen.

\section{Notdienst an Vertragsarztsitz gekoppelt}

Dies geschah zu Unrecht, urteilte das LSG Baden-Württemberg, und hob die anderslautenden Bescheide der KZV und das Urteil des Sozialgerichts Stuttgart auf, das diese Bescheide bestätigt hatte.

Die KZV gehe zu Unrecht von zwei Praxen beziehungsweise zwei Zulassungen aus, die beide Notfalldienstverpflichtungen hätten. Dies sei bereits mit $\$ 95$ SGB V nicht zu vereinbaren. Die Pflicht zur Teilnahme am Notfalldienst folge aus dem Versorgungsauftrag. Jedem Zahnarzt könne nur ein Vertragsarztsitz mit jeweils maximal einem vollen Versorgungsauftrag zugeordnet werden. Maximal im Umfang dieses Auftrags dürfe der Zahnarzt auch zum Notdienst herangezogen werden. Eine Zweigpraxis verdoppelt die Zulassung oder den Versorgungsauftrag und damit die Heranziehung zum Notdienst nicht.

Gründe der Erreichbarkeit für die Patienten geböten ebenfalls keine doppelte Einteilung. Der Notdienst sei so organisiert, dass es den Patienten zugemutet werde, sich im gesamten Notfalldienstbezirk zum jeweils diensthabenden Zahnarzt zu begeben. Demnach sei die Entscheidung auch nicht mit dem Sicherstellungsauftrag gemäß $₫ 75$ Abs. 1 S. 2 SGB V der KZV sowohl am Hauptstandort als auch am Ort der Zweigpraxis zu rechtfertigen.

Wegen der im Wesentlichen auf Bundesrecht, dem SGB V, gestützten Begründung hat das Urteil Bedeutung über BadenWürttemberg hinaus.

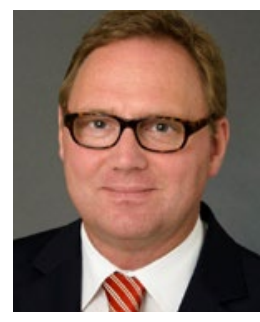

RA Michael Lennartz www.heilberufe.eu 